\title{
Effect of duration and level of supplementation of diets of lactating dairy cows with selenized yeast on selenium concentrations in milk and blood after the withdrawal of supplementation
}

\author{
C. R. Stockdale ${ }^{\star 1,2}$ and H. S. Gill† \\ *Department of Primary Industries, Future Farming Systems Research Division, Kyabram Centre, 120 Cooma Road, \\ Kyabram Victoria 3620, Australia \\ †Department of Primary Industries, Future Farming Systems Research Division, Werribee Centre, 600 Sneydes Road, \\ Werribee Victoria 3030, Australia
}

\section{ABSTRACT}

Cows' milk containing elevated concentrations of Se provides a rich nutritional source of this essential element for meeting daily nutritional requirements or providing health benefits in humans with low immune function or at risk of cancer. An experiment involving either 2 or 6 wk of dietary supplementation with Se yeast (with the yeast supplying about 30, 40, and 60 $\mathrm{mg}$ of Se/d for cows supplemented for $2 \mathrm{wk}$, and about 20, 30, 40, and $60 \mathrm{mg}$ of $\mathrm{Se} / \mathrm{d}$ for cows supplemented for $6 \mathrm{wk}$ ), and $21 \mathrm{wk}$ of monitoring of Se status after the withdrawal of supplementation, was undertaken between September 2008 and April 2009 using 35 multiparous Holstein-Friesian cows. Using milk and blood Se concentrations as surrogates, the research examined the time taken for Se build-up in tissue due to supplementation of lactating dairy cows with Se yeast to dissipate back to normal levels. At the end of Se supplementation, a significant relationship was found between milk Se concentration and Se intake, whereby milk Se concentration had increased by $4.5 \mu \mathrm{g}$ of Se/ $\mathrm{kg}$ of milk for each mg of Se eaten per day, but no effect of duration of supplementation on this relationship was observed. At the same time, both Se intake and duration of supplementation affected blood Se concentration; it increased by $3.6 \mu \mathrm{g}$ of $\mathrm{Se} / \mathrm{kg}$ of blood for each mg of Se eaten per day, and was $86 \mu \mathrm{g}$ of Se $/ \mathrm{kg}$ higher after 6 wk compared with 2 wk of supplementation. After the withdrawal of Se supplementation, milk Se concentrations responded quickly to the change in the quantity of Se consumed, and again, duration of supplementation had no effect on the response, but any effect that Se intake had on milk Se had completely dis-

\footnotetext{
Received September 30, 2010.

Accepted February 1, 2011.

${ }^{1}$ Corresponding author: richard.stockdale@dpi.vic.gov.au

${ }^{2}$ Current address: Department of Primary Industries, Future Farming Systems Research Division, Tatura Centre, Private Bag 1, 255 Ferguson Road, Tatura Victoria 3616, Australia
}

sipated by 4 wk. In contrast to milk, blood Se concentrations continued to be affected by both amount and duration of Se supplementation for at least 4 mo after the withdrawal of supplementation, although by 5 mo the effects of the previous supplementation treatments had virtually disappeared. The slow decline in blood Se concentrations after the withdrawal of supplementation would most likely be due to the protracted clearance of Se from the various tissues that had accumulated Se during supplementation and the rate of erythrocyte turnover. When undertaking an on-farm Se enhancement program to generate milk for the manufacture of Se-enriched milk products, post-supplementation milk Se concentrations are unlikely to create any problems at the milk factory beyond $4 \mathrm{wk}$, but the high residual blood/tissue Se concentrations that take considerably more time to dissipate may provide the potential for possible unintended consequences at the food chain/ farm environment level.

Key words: selenium yeast, milk and blood selenium, residual selenium, dairy cow

\section{INTRODUCTION}

Selenium provided from an organic source such as Se yeast, when used to supplement the diets of lactating dairy cows, can increase Se concentrations in milk (Weiss, 2003; Ceballos et al., 2009) so that dairy products could be used to meet recommended daily intakes for humans $(55 \mu \mathrm{g} / \mathrm{d})$ or in preventive health where 150-200 $\mu \mathrm{g} / \mathrm{d}$ might be needed (McIntosh et al., 2008). Weiss (2003) and Ceballos et al. (2009) reported that supplementing the diet of cows with Se yeast was more effective at increasing the concentration of Se in milk than similar amounts of Se from inorganic forms. Moreover, the bioavailability of an organic source of Se that had been incorporated into milk has also been shown to be greater than Se from other sources in pigs (McIntosh et al., 2008; Uglietta et al., 2008), and has been significantly more effective at preventing chemically-induced colorectal cancer in mice (Hu et al., 2008). 
Large quantities of Se have been fed to dairy cows in recent studies to either test the tolerance of the animals and their subsequent health to high doses of Se (Juniper et al., 2008a) or to provide milk with specific high Se concentrations for the manufacture of Se-enriched milk products for preventive health in humans (Heard et al., 2007; Walker et al., 2010; Stockdale et al., 2011). The amounts of organic Se needed to produce Se-enriched milk and dairy products may be up to 50 times higher than that needed to prevent Se deficiency in livestock. Currently, these levels of Se intake are not permitted in some regions because of legislative restrictions (e.g., in the United States, FDA regulations limit Se supplementation to $0.3 \mathrm{mg} / \mathrm{kg}$ of $\mathrm{DM}$ ), whereas in other areas, recommended levels of intake exist, rather than legislative requirements.

Invariably, milk and blood Se concentrations have been positively related to Se intake (Givens et al., 2004; Juniper et al., 2006; Walker et al., 2010), and it is currently technically feasible to produce high Se concentrations in milk on-farm (Doyle et al., 2011), but little information is available on the persistency of Se in milk and blood/tissues when Se supplementation ceases. After the withdrawal of the Se, milk Se concentrations seem to decrease more quickly than blood and tissue Se concentrations (Heard et al., 2007). High residual tissue Se concentrations can act as a reserve in times of dietary Se deficiency (Taylor, 2005; Juniper et al., 2008c), but they also provide the potential for possible unintended consequences at the farm/environment level. If animals are sold after high Se supplementation, this may create issues in another food chain, and the re-entry of tissue Se into the bloodstream could sustain higher levels of excretion of Se to the environment than desired. With only one study published on the persistency of Se in tissues following the withdrawal of dietary Se yeast (Juniper et al., 2008b), and that was in lambs, currently no information exists on how duration of supplementation or amount of Se yeast fed might affect residual responses in dairy cattle.

Using milk and blood Se concentrations as surrogates, the objective of the research described here was to examine the time taken for Se build-up in tissue due to supplementation of lactating dairy cows with Se yeast to dissipate back to normal levels after the withdrawal of supplementation. It was hypothesized that the length of time taken for concentrations of Se in milk and blood to return to base levels after the cessation of Se supplementation of lactating dairy cows would be positively associated with duration of supplementation and amount of Se yeast fed.

\section{MATERIALS AND METHODS}

An experiment involving either 2 or 6 wk of dietary supplementation with Se yeast, and 21 wk of monitoring after the withdrawal of supplementation, was undertaken between September 2008 and April 2009 using 35 multiparous Holstein-Friesian cows. The experiment was conducted at the Victorian Department of Primary Industries' Kyabram Center $\left(36^{\circ} 20^{\prime} \mathrm{S}, 145^{\circ} 04^{\prime} \mathrm{E}\right)$ in northern Victoria. All procedures were conducted with protocols approved by the Animal Ethics Committee of the Department of Primary Industries.

\section{Experimental Design and Feeding}

Of the 35 cows used, 20 were supplemented with 2 $\mathrm{kg} / \mathrm{d}$ of Se-enriched pellets for 6 wk while grazing an irrigated perennial ryegrass (Lolium perenne L.) pasture oversown with oats (Avena sativa L.) at a daily allowance of about $30 \mathrm{~kg}$ of $\mathrm{DM} / \mathrm{cow}$. The pellets provided about 20,30,40, or $60 \mathrm{mg}$ of Se from Se yeast produced from Saccharomyces cerevisiae CNCM I-3060 (Sel-Plex; Alltech Biotechnology, Nicholasville, KY), which was included in the cereal grain-based pellets manufactured at a commercial pelleting plant. Supplementation treatments were imposed on the remaining 15 cows for the final $2 \mathrm{wk}$ of the 6 -wk supplementation period, and 2 $\mathrm{kg} / \mathrm{d}$ of pellets providing 30,40 , or $60 \mathrm{mg}$ of supplemental Se were fed to these cows. Low and high Se pellets (Table 1) were mixed in different proportions to achieve the appropriate quantities of supplemental Se. There were 5 cows per treatment.

Data were collected during the 2 wk before the experiment for selection of cows and allocation to treatment, and for correction of data for between-cow variation. Cows were allocated to treatments by stratified randomization based on milk yield $(35.6 \pm 5.32$ $\mathrm{kg} / \mathrm{d})$, milk protein concentration $(3.18 \pm 0.318 \%)$, BCS (4.4 \pm 0.42 units on the 8-point scale of Earle 1976), and BW (534 $\pm 46.5 \mathrm{~kg})$ before the experiment began using Baird's method (Baird, 1994) in Genstat 10 (2007, Lawes Agricultural Trust, Rothamsted, UK). Cows were individually fed their Se supplement, but they grazed together as one group throughout the 6-wk supplementation period. All cows were offered half of their pelleted supplement immediately following the a.m. milking, and the other half immediately following the p.m. milking. After being allowed sufficient time to consume their supplement, the cows returned to pasture for grazing. Cows were offered half of their daily pasture allowance after the a.m. milking and the remaining 
Table 1. Nutritive characteristics of the pasture and supplements consumed by the cows in the experiment $($ mean $\pm \mathrm{SD})$

\begin{tabular}{|c|c|c|c|c|}
\hline \multirow[b]{2}{*}{ Item } & \multirow[b]{2}{*}{ Pasture } & \multirow[b]{2}{*}{ Pellets } & \multicolumn{2}{|c|}{ Se-enhanced pellets ${ }^{1}$} \\
\hline & & & Low Se & High Se \\
\hline \multicolumn{5}{|l|}{ 6-wk duration } \\
\hline ME (MJ/kg of DM) & $12.0( \pm 0.98)$ & $11.6( \pm 0.10)$ & $12.1( \pm 0.08)$ & $12.1( \pm 0.07)$ \\
\hline $\mathrm{CP}(\%$ of $\mathrm{DM})$ & $19.4( \pm 5.47)$ & $14.3( \pm 0.37)$ & $14.1( \pm 0.14)$ & $14.6( \pm 0.06)$ \\
\hline $\mathrm{NDF}(\%$ of $\mathrm{DM})$ & $41.2( \pm 5.94)$ & $20.1( \pm 0.80)$ & $17.3( \pm 0.50)$ & $17.4( \pm 0.41)$ \\
\hline $\mathrm{Se}(\mu \mathrm{g} / \mathrm{kg}$ of $\mathrm{DM})$ & $58( \pm 17.5)$ & $455( \pm 24.2)$ & $10,222( \pm 1,873.1)$ & $34,088( \pm 2,700.6)$ \\
\hline \multicolumn{5}{|l|}{2 -wk duration } \\
\hline $\mathrm{ME}(\mathrm{MJ} / \mathrm{kg}$ of $\mathrm{DM})$ & $10.8( \pm 0.37)$ & $11.6( \pm 0.13)$ & $12.1( \pm 0.02)$ & $12.1( \pm 0.12)$ \\
\hline $\mathrm{CP}(\%$ of $\mathrm{DM})$ & $14.9( \pm 0.88)$ & $14.7( \pm 0.22)$ & $14.2( \pm 0.18)$ & $14.7( \pm 0.04)$ \\
\hline NDF ( $\%$ of DM) & $47.9( \pm 1.91)$ & $20.3( \pm 1.06)$ & $17.7( \pm 0.21)$ & $17.6( \pm 0.49)$ \\
\hline Se $(\mu \mathrm{g} / \mathrm{kg}$ of $\mathrm{DM})$ & $72( \pm 11.3)$ & $470( \pm 41.6)$ & $12,524( \pm 613.1)$ & $34,844( \pm 505.9)$ \\
\hline
\end{tabular}

${ }^{1}$ Pellets were mixed to provide approximate daily quantities of Se of $20,30,40$, and $60 \mathrm{mg} / \mathrm{cow}$.

pasture after the p.m. milking. Other than pasture and Se-enriched pellets, the only other ingredient in the diet of the cows was $1 \mathrm{~kg}$ of concentrates in the dairy at each milking to encourage cows to enter the platform to be milked. After the 6 -wk supplementation treatment period, the cows returned to the Kyabram Center herd for monitoring of milk and blood Se concentrations for the next $21 \mathrm{wk}$, and were fed a mixture of grazed perennial pasture, oaten and alfalfa (Medicago sativa L.) hay, and cereal grain-based concentrates (with a Se concentration of about $0.4 \mathrm{mg} / \mathrm{kg}$ of DM). Based on milk yield and composition, it was estimated that average daily DMI during this period was about $18 \mathrm{~kg} /$ cow.

\section{Measurements}

Pasture intakes of individual cows were estimated using the Diet Check nutrition model (Heard et al., 2004a). Each week, a bulked pasture sample (collected on Monday and Thursday), representative of pasture consumed by cows (samples cut to a simulated grazing height of $4 \mathrm{~cm}$ ), was collected by cutting a minimum of 15 small quadrats along a fixed transect across the area to be grazed by the next sampling day. Representative subsamples of approximately $100 \mathrm{~g}$ of fresh weight were oven-dried at $60^{\circ} \mathrm{C}$ for $72 \mathrm{~h}$, ground through a $0.5-\mathrm{mm}$ screen, and stored for subsequent analysis. In vitro DM digestibility (IVDMD), CP, and NDF content were determined using near infrared reflectance spectroscopy (NIRS; FeedTest, Hamilton, Australia) and estimated $\mathrm{ME}(\mathrm{MJ} / \mathrm{kg}$ of $\mathrm{DM})$ was calculated using the equation $0.17 \times$ IVDMD -2.0 (Standing Committee on Agriculture, 1990).

The amounts of Se-enriched pellets offered to, and refused by, each cow were weighed daily, and DM contents were calculated by drying samples at $100^{\circ} \mathrm{C}$ for 24 h. Weekly samples of pellets and the concentrates fed in the dairy were taken throughout the experimental period, dried at $60^{\circ} \mathrm{C}$, ground and analyzed for IVD$\mathrm{MD}, \mathrm{CP}$, and NDF concentrations as described above. Estimated ME concentrations $(\mathrm{MJ} / \mathrm{kg}$ of $\mathrm{DM})$ were calculated using the equation $0.134 \times$ IVDMD +0.235 $\times \mathrm{EE}+1.23(\mathrm{CSIRO}, 2007)$, where EE is ether extract (assumed to be $2 \%$ ).

Cows were milked at 0530 and $1600 \mathrm{~h}$ each day and individual milk yields were measured at each milking before the experiment began and throughout the experimental and monitoring periods. Aliquot samples from each cow were taken at an a.m. and p.m. milking once before the experiment began, every 2 wk during Se supplementation, and at approximately 4-wk intervals thereafter until April 2009. These samples were analyzed for fat, protein and lactose concentrations, and SCC, by a Foss 4000/5000 Combi (Foss Electric, Hillerød, Denmark). On each occasion, milk samples from each cow were also stored for the analysis of Se concentration after the a.m. and p.m. aliquots were combined. Cows were weighed and their BCS assessed (Earle, 1976) before treatments commenced and every 2 wk thereafter for the duration of the experimental period.

Blood samples were taken from the coccygeal vein of each cow for analysis of whole blood Se concentration at the same time that milk samples were collected for Se analysis. Blood sampling took place in the a.m. after the cows had been fed their supplements. Samples were collected into 10-mL Vacutainers (Becton Dickinson Australia, North Ryde, NSW, Australia) containing lithium heparin, immediately put on ice, and stored within $1 \mathrm{~h}$ at $-80^{\circ} \mathrm{C}$ to await analysis.

The concentration of total Se in all samples (feeds, milk, whole blood) was determined by inductively coupled plasma mass spectrometry/vapor generation (Varian Australia Pty. Ltd., Mulgrave, VCI, Australia), following digestion of samples in a mixture of nitric and perchloric acids, as described by Heard et al. (2007). 
Table 2. Estimated daily DMI and Se intake for all treatments averaged across the whole experimental period

\begin{tabular}{|c|c|c|c|c|c|c|c|}
\hline \multirow[b]{3}{*}{ Item } & \multicolumn{7}{|c|}{ Se treatment ${ }^{1}$} \\
\hline & \multicolumn{3}{|c|}{ 2-wk duration } & \multicolumn{4}{|c|}{ 6-wk duration } \\
\hline & 30 & 40 & 60 & 20 & 30 & 40 & 60 \\
\hline \multicolumn{8}{|l|}{ DMI (kg/cow) } \\
\hline Dairy pellets & 1.6 & 1.8 & 1.8 & 1.8 & 1.8 & 1.8 & 1.8 \\
\hline Se pellets & 1.7 & 1.7 & 1.8 & 1.8 & 1.7 & 1.8 & 1.8 \\
\hline Pasture & 16.8 & 16.0 & 17.4 & 16.0 & 16.0 & 16.3 & 15.7 \\
\hline Total & 20.1 & 19.5 & 21.0 & 19.6 & 19.5 & 19.9 & 19.3 \\
\hline \multicolumn{8}{|c|}{ Se intake (mg/cow) } \\
\hline Dairy pellets & 0.75 & 0.85 & 0.85 & 0.82 & 0.82 & 0.82 & 0.82 \\
\hline Se pellets & 30.78 & 40.26 & 62.72 & 18.40 & 27.52 & 39.88 & 61.36 \\
\hline Pasture & 1.21 & 1.15 & 1.25 & 0.93 & 0.93 & 0.95 & 0.91 \\
\hline Total & 32.74 & 42.26 & 64.82 & 20.15 & 29.27 & 41.65 & 63.09 \\
\hline
\end{tabular}

${ }^{1}$ Pellets to provide nominal daily quantities of Se of $20,30,40$, and $60 \mathrm{mg} / \mathrm{cow}$.

\section{Statistical Analysis}

Animal production responses to the Se quantity and duration treatments were compared by analysis of covariance employing a randomized block design, with 5 replicates, using Genstat 10 (2007, Lawes Agricultural Trust). Treatment responses for milk and blood Se concentrations were compared by repeated measures analysis of covariance, using the data commencing from the end of Se supplementation. Repeated measures analysis of covariance was also used specifically for the milk Se data collected during the 6 wk of Se supplementation, when cows were under treatment. A cow was the experimental unit, and significant differences were established at $P=0.05$.

Using mean data for treatments, relationships between milk or blood Se concentration $(\mathrm{Y} ; \mu \mathrm{g} / \mathrm{kg})$ and total Se intake (X; mg/d) were examined by stepwise regression analysis in Genstat 10 (2007, Lawes Agricultural Trust) according to the following model:

$\mathrm{Y}=\mathrm{a}+\mathrm{b} \times \mathrm{X}+\mathrm{c} \times$ Duration $+\mathrm{d} \times \mathrm{X} \times$ Duration

where Duration $=$ a pseudovariable to distinguish between $2(0)$ and $6(+1)$ wk of Se supplementation; $\mathrm{X} \times$ Duration $=$ the first-order interaction; and $\mathrm{a}, \mathrm{b}, \mathrm{c}$, and $\mathrm{d}$ are coefficients. Both Se intake and Duration were initially tested, and a variable was only included in the regression if it was significant at $P<0.05$. Providing that at least 1 of the main variables was significant, the interaction was then tested to determine whether it could be added. Because the data from each sampling time were analyzed separately, a Bonferroni correction (used to address the issue of multiple comparisons for several time points) was applied to the $P$-value of any resulting equation, such that the $P$-value for declaring significance was decreased from 0.05 to 0.007 .

\section{RESULTS}

Details of the nutritive characteristics of the dietary ingredients, and the quantities of the feeds consumed, are given in Tables 1 and 2. The pasture on offer was dominated by oats early in the supplementation period, but changed to ryegrass dominance toward the end. This affected ME concentrations, which were in the range of 12.2 to $13.0 \mathrm{MJ} / \mathrm{kg}$ of $\mathrm{DM}$ early in the 6-wk period, but had decreased to $10.8 \mathrm{MJ} / \mathrm{kg}$ of $\mathrm{DM}$ during the last 2 wk. The major source of Se was the Se-enriched pellets, which had either 10 to 13 or 34 to $35 \mathrm{mg}$ of $\mathrm{Se} / \mathrm{kg}$ of DM (Table 1). By proportionally mixing these pellets, the nominal daily quantities of Se of $20,30,40$, and $60 \mathrm{mg} / \mathrm{cow}$ were approximately achieved (Table 2). No effect of amount of Se fed or of duration of supplementation with Se-enriched pellets was observed on any aspect of animal production during the period of Se supplementation (Table 3) or during the post-supplementation monitoring period (data not shown).

Milk Se concentrations (Figure 1a) increased as Se intake increased in cows supplemented for both 2 and 6 wk. At wk 6 of the experiment, milk Se concentrations had increased by $4.5 \mu \mathrm{g} / \mathrm{kg}$ for each milligram of Se consumed per day, but this was not affected by duration of supplementation (Table 4; i.e., for those cows supplemented with Se for $2 \mathrm{wk}$, milk Se concentrations were similar to those where cows had been supplemented for 6 wk; Figure 1a). For those cows supplemented with Se for $6 \mathrm{wk}$, milk Se concentrations had reached apparent steady state at wk 2 and 4 at all levels of Se supplementation before increasing markedly in all treatments at wk 6 . This response was consistent for treatment means analyzed by regression (Figure 2) and for individual cow data interrogated by repeated measures analysis of covariance [means of 111 (wk 2) and 113 (wk 4) 
Table 3. The effect of Se supplementation on aspects of covariate-corrected daily milk production, and BW, BCS, and pasture DMI averaged over the experimental period

\begin{tabular}{|c|c|c|c|c|c|c|c|c|}
\hline \multirow[b]{2}{*}{ Item } & \multicolumn{3}{|c|}{ 2-wk Se supplementation ${ }^{1,2}$} & \multicolumn{4}{|c|}{6 -wk Se supplementation ${ }^{1,2}$} & \multirow[b]{2}{*}{$P$-value } \\
\hline & 30 & 40 & 60 & 20 & 30 & 40 & 60 & \\
\hline Milk fat $(\%)$ & 3.94 & 4.06 & 4.01 & 3.94 & 3.74 & 4.06 & 4.16 & 0.206 \\
\hline Milk protein (\%) & 3.15 & 3.18 & 3.18 & 3.18 & 3.19 & 3.17 & 3.21 & 0.924 \\
\hline Milk lactose (\%) & 5.04 & 4.97 & 5.01 & 5.00 & 5.02 & 4.99 & 4.99 & 0.235 \\
\hline Fat yield (kg/cow) & 1.25 & 1.26 & 1.30 & 1.22 & 1.15 & 1.26 & 1.30 & 0.080 \\
\hline $\mathrm{SCC}(\times 1,000)$ & 42 & 54 & 21 & 51 & 42 & 63 & 55 & 0.327 \\
\hline BW (kg) & 550 & 544 & 548 & 546 & 548 & 547 & 546 & 0.864 \\
\hline $\mathrm{BCS}^{3}$ (units) & 4.4 & 4.3 & 4.5 & 4.3 & 4.3 & 4.4 & 4.5 & 0.139 \\
\hline Pasture DMI (kg/cow) & 16.8 & 16.0 & 17.4 & 16.0 & 16.0 & 16.3 & 15.7 & 0.835 \\
\hline
\end{tabular}

${ }^{1}$ Pellets to provide nominal daily quantities of Se of $20,30,40$, and $60 \mathrm{mg} / \mathrm{cow}$.

${ }^{2}$ Supplementation of Se-enriched pellets for either 2 or $6 \mathrm{wk}$.

${ }^{3}$ On the 8-point scale of Earle (1976).

versus 185 (wk 6) $\mu \mathrm{g}$ of Se/kg of milk; $P<0.001 ; \mathrm{LSD}$ $=25.9$. After Se supplementation was withdrawn, neither regression analysis of treatment means (Table 4) nor repeated measures analysis of individual cow data indicated any differences between any treatments or post-supplementation sampling times $(\mathrm{LSD}=11.0$ ).

Blood Se concentrations increased by $3.6 \mu \mathrm{g} / \mathrm{kg}$ for each milligram of Se consumed per day, and at the end of supplementation, blood Se concentration was higher in those cows supplemented for $6 \mathrm{wk}$ compared with those only supplemented for 2 wk (Table 4; Figure 1b). Blood Se concentrations increased throughout supplementation, and cows supplemented for $2 \mathrm{wk}$ had similar blood Se concentrations to those at $2 \mathrm{wk}$ in those cows supplemented for 6 wk (Figure 1b). For the cows supplemented for $6 \mathrm{wk}$, blood Se concentrations rose with each successive sampling time, and were 211, 251 , and $302 \mu \mathrm{g}$ of $\mathrm{Se} / \mathrm{kg}$ of blood, on average, at wk 2,4 , and 6 , respectively $(P<0.001 ; \mathrm{LSD}=5.4)$. Duration and Se intake differences persisted with blood Se concentrations until the last sampling at $21 \mathrm{wk}$ after the withdrawal of supplementation (Table 4; Figure 1b; LSD $=27.5)$. Responses to both duration and intake of Se decreased with time (Table 4). At no time, with either milk or blood Se concentrations, was there any indication of a significant interaction between amount of Se consumed and duration of supplementation.

\section{DISCUSSION}

Our hypothesis, that the length of time taken for concentrations of Se in milk and blood to return to normal levels after the withdrawal of Se supplementation of lactating dairy cows would be positively associated with duration of supplementation and amount of $\mathrm{Se}$ yeast fed, was supported by the results of the current experiment for whole blood, but not for milk. Milk Se concentrations responded very quickly to change in Se consumption, whereas duration of supplementation was not implicated in the response at any stage. The effect of Se intake had completely dissipated by $4 \mathrm{wk}$ after Se supplementation had been withdrawn, with all treatments averaging $26 \mu \mathrm{g}$ of $\mathrm{Se} / \mathrm{kg}$ of milk thereafter. This result is supported by the recent research of Heard et al. (2007) and Stockdale et al. (2011). Heard et al. (2007) monitored milk Se concentrations in 2 doseresponse experiments (in which up to $18 \mathrm{mg}$ of $\mathrm{Se} / \mathrm{d}$ had been fed for $6 \mathrm{wk}$ ) for $3 \mathrm{wk}$ after the withdrawal of Se supplementation and found that treatment effects were no longer evident by the end of monitoring in one experiment, but not in the other. Stockdale et al. (2011) monitored Se concentrations for 9 wk after supplementation with up to $37 \mathrm{mg}$ of Se/d for $6 \mathrm{wk}$ and found that the effects of Se treatment were no longer evident beyond 3 wk post-supplementation. Therefore, in the event that high-Se milk is being delivered to a milk factory for the manufacture of a Se-enriched product, it could be anticipated that post-supplementation milk Se concentrations should return to normal levels within 3 to 4 wk of withdrawal of Se supplementation, at least where no more than $60 \mathrm{mg}$ of $\mathrm{Se} / \mathrm{d}$ has been fed. Residual concentrations of 20 to $30 \mu \mathrm{g}$ of Se/ $\mathrm{kg}$ of milk, as found here and by Heard et al. (2007) and Stockdale et al. (2011), are unlikely to affect the operations of a factory unless Se specifications for other factory products are being exceeded by this amount of Se (e.g., some infant formulas can be sensitive to any elevation in milk Se).

In contrast to milk, blood Se concentrations continued to be affected by both amount and duration of Se 

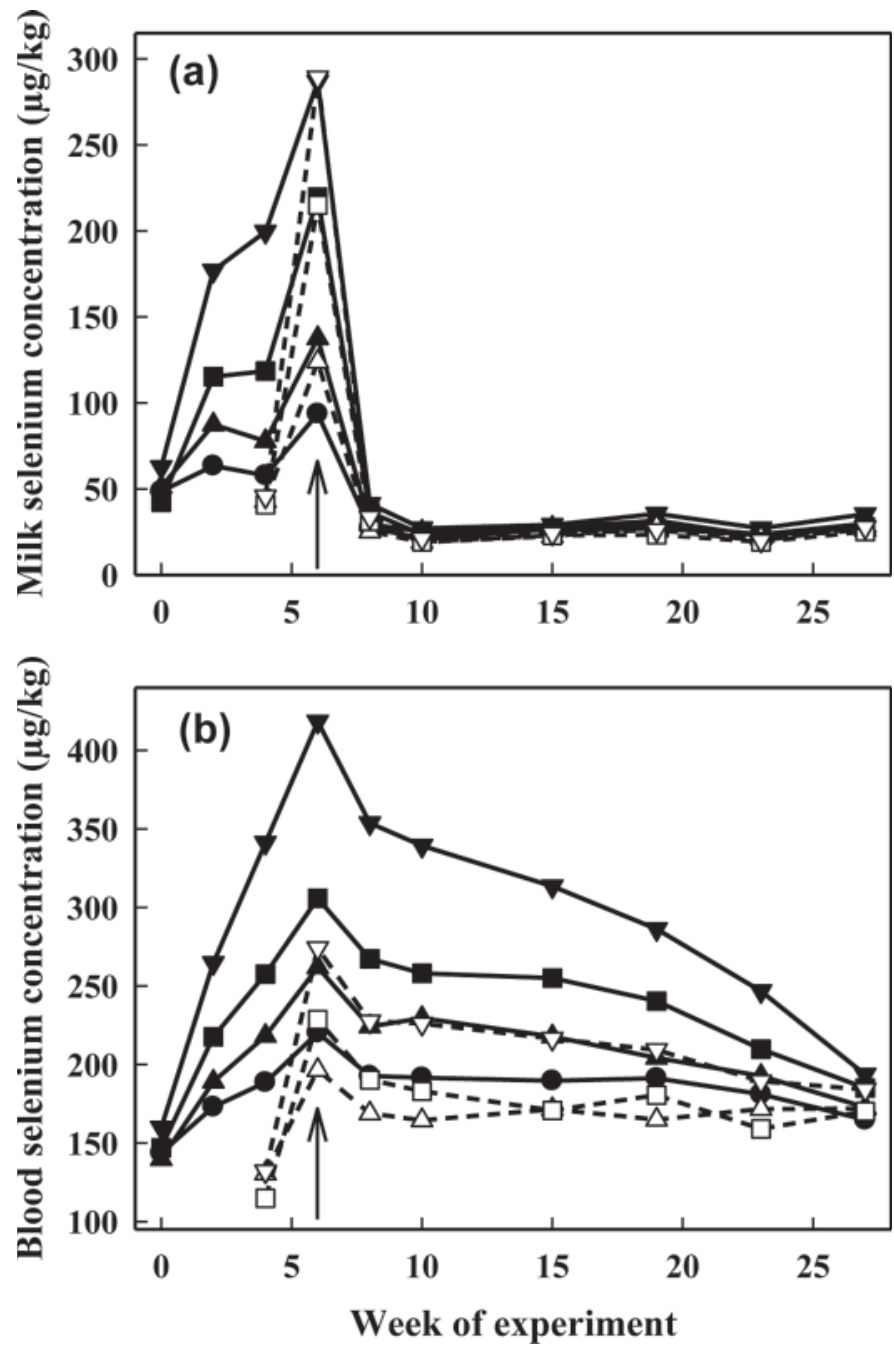

Figure 1. Milk (a) and blood (b) Se concentrations throughout the experiment for those cows supplemented with Se yeast for $2 \mathrm{wk}(\triangle 30$ $\mathrm{mg}$ of Se/d; $\square 40 \mathrm{mg}$ of Se/d; $\nabla 60 \mathrm{mg}$ of Se/d) and $6 \mathrm{wk} \bullet 20 \mathrm{mg}$ of Se/d; $\boldsymbol{\Delta} 30 \mathrm{mg}$ of Se/d; $40 \mathrm{mg}$ of Se/d; $\boldsymbol{\nabla} 60 \mathrm{mg}$ of Se/d). The arrows indicate the end of Se supplementation. Significant responses at each sampling time to Se intake and duration of supplementation are given in Table 4.

supplementation for at least 4 mo after the withdrawal of supplementation, although by 5 mo, these prior treatment effects had virtually dissipated. The slow decrease in blood Se concentrations is supported by the results reported by Stockdale et al. (2011) for 9 wk of post-supplementation monitoring. After the withdrawal of supplementation, the decrease in blood Se concentrations will depend on erythrocyte turnover and the rate of clearance of Se from the various tissues that have accumulated Se during supplementation. In sheep and beef, metabolically active tissues such as the liver and kidney accumulate the greatest concentrations of Se, with cardiac muscle being intermediate, and skeletal tissue having the lowest concentrations (Taylor, 2005;
Juniper et al., 2008c, 2009). Juniper et al. (2008b) reported that after supplementation, the rate of clearance of Se from tissues of lambs occurred in the same order, with liver and kidney being fastest and skeletal muscle slowest. Following the withdrawal of supplementation, they measured average clearance rates of 307, 238, 120, and $20 \mu \mathrm{g}$ of Se/d for liver, kidney, heart, and skeletal muscle, respectively. Juniper et al. (2008b) estimated that the Se concentrations of kidney, liver, and heart would decrease to those of unsupplemented control animals by 55,70 , and $80 \mathrm{~d}$, respectively, after supplementation ceased, whereas extrapolation of the skeletal muscle data indicated that it could require a period well in excess of $300 \mathrm{~d}$. If supranutritional quantities of Se are fed on-farm to produce milk for the manufacture of Se-enriched health products, farmers need to be aware that unintended consequences could occur if culled animals enter a food chain that may be sensitive to excess Se, or excreta could potentially become an environmental hazard, particularly to wildlife (Lemly, 2004), for some time after the supplementation of large quantities of Se has ceased.

Conversely, a benefit of this response is that enhancement of tissue Se could provide endogenous Se stores at a level that could offset a potential deficiency in animals grazing Se-deficient grasslands (i.e., increasing tissue Se depots by feeding Se yeast could provide a long-term slow-release source of Se; Taylor, 2005; Juniper et al., 2008c). The Se-loading potential of Se yeast, where the major single Se component is Se-methionine (SeMet) at 62 to $74 \%$, seems to be because of the biochemical similarity of SeMet and methionine (Rayman, 2004). Because of a unique interchangeability between the 2 during translation, SeMet has the capacity to be assimilated nonspecifically into normal body proteins in place of methionine, thus acting as a potential reservoir for Se (Combs, 2001). The SeMet that is incorporated into actively regenerating body proteins can then be removed during the degradation and resynthesis of proteins and transformed to selenide for utilization or excretion (Schrauzer, 2003).

Milk Se concentrations achieved by feeding up to 60 mg of Se yeast/cow per day were not particularly consistent with those reported previously. Providing cows consume all their Se supplements, it has been clearly demonstrated that milk Se concentrations can reach a steady state by 1 wk after the introduction of Se yeast (McIntosh and Royle, 2002; Heard et al., 2004b, 2007). With those cows that were supplemented for $6 \mathrm{wk}$, this appeared to have occurred until the final sampling at wk 6 of the treatment period, when a marked increase in milk Se concentration was recorded (Figures 1a and 2 ). The results early in the 6 -wk period are corroborated by those reported by Stockdale and Gill (2010) 


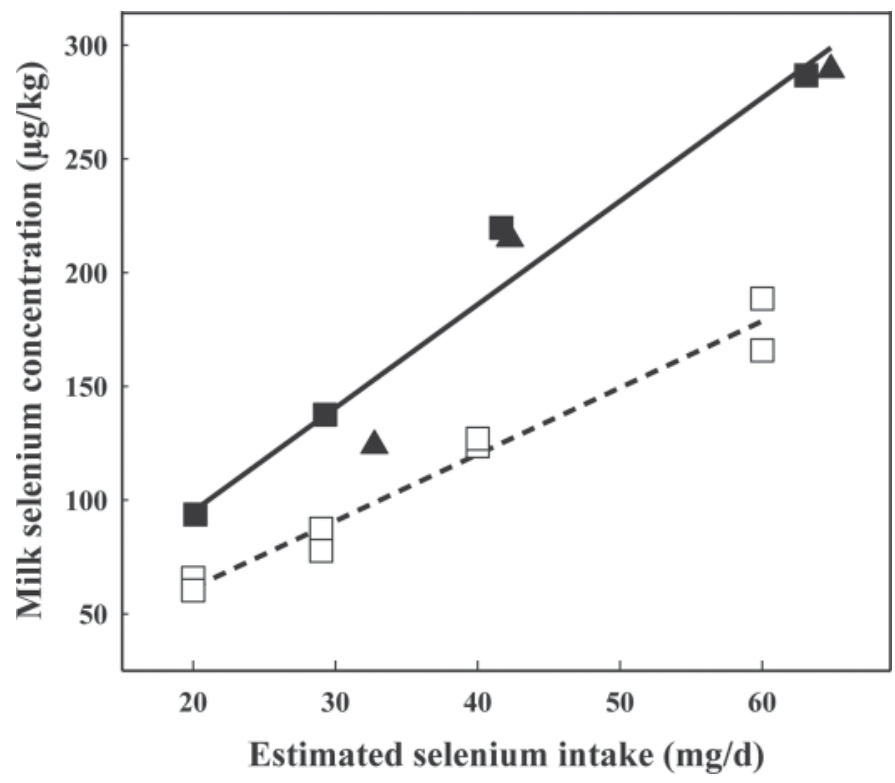

Figure 2. The milk Se concentration/Se intake relationship at wk $2 / 4\left(\square ; \mathrm{R}^{2}=0.972, P<0.001\right)$ compared with that at wk 6 for cows that were supplemented with Se for 6 wk $(\boldsymbol{\square})$ and at wk 2 for the cows that were supplemented with Se for 2 wk $\left(\boldsymbol{\Lambda} ; \mathrm{R}^{2}=0.946, P<0.001\right.$; this relationship is recorded in Table 4). from an associated experiment being undertaken at the same time, whereas the data generated at 6 wk are supported by the results for the 2 -wk treatments. The cause of the sudden increase is not clear, but the change in the pasture on offer, from oat dominance to perennial ryegrass dominance, with an associated decrease in ME concentration of the herbage from 13.0 to 10.8 $\mathrm{MJ} / \mathrm{kg}$ of DM across the 6 wk of supplementation, may be implicated. The higher ME concentrations may have decreased the availability of Se from the yeast, as Wales et al. (1999) reported that the effective rumen degradability of herbage was positively related to its DM digestibility up to about $85 \%$ digestibility. Moreover, Mayland (1994) reported that rumen microorganisms can incorporate dietary SeMet into their own protein, but can also reduce dietary Se into inorganic forms that are largely unavailable to the ruminant. Whatever the mechanisms involved, milk Se responses can be variable and, currently, the causes for this variation have not been determined.

Although quantities of Se above those needed to meet animal requirements were fed in the current experiment, no adverse effects on animal production were observed, a result supported by most previous research with milk

Table 4. Relationships ${ }^{1}$ between milk or blood Se concentration $(\mu \mathrm{g} \mathrm{Se} / \mathrm{kg})$ and total Se intake (SeI; mg/d) and duration of supplementation (D; $2 \mathrm{wk}=0,6 \mathrm{wk}=+1$; refer to Materials and Methods for full explanation) from the end of supplementation and through the 21-wk monitoring period

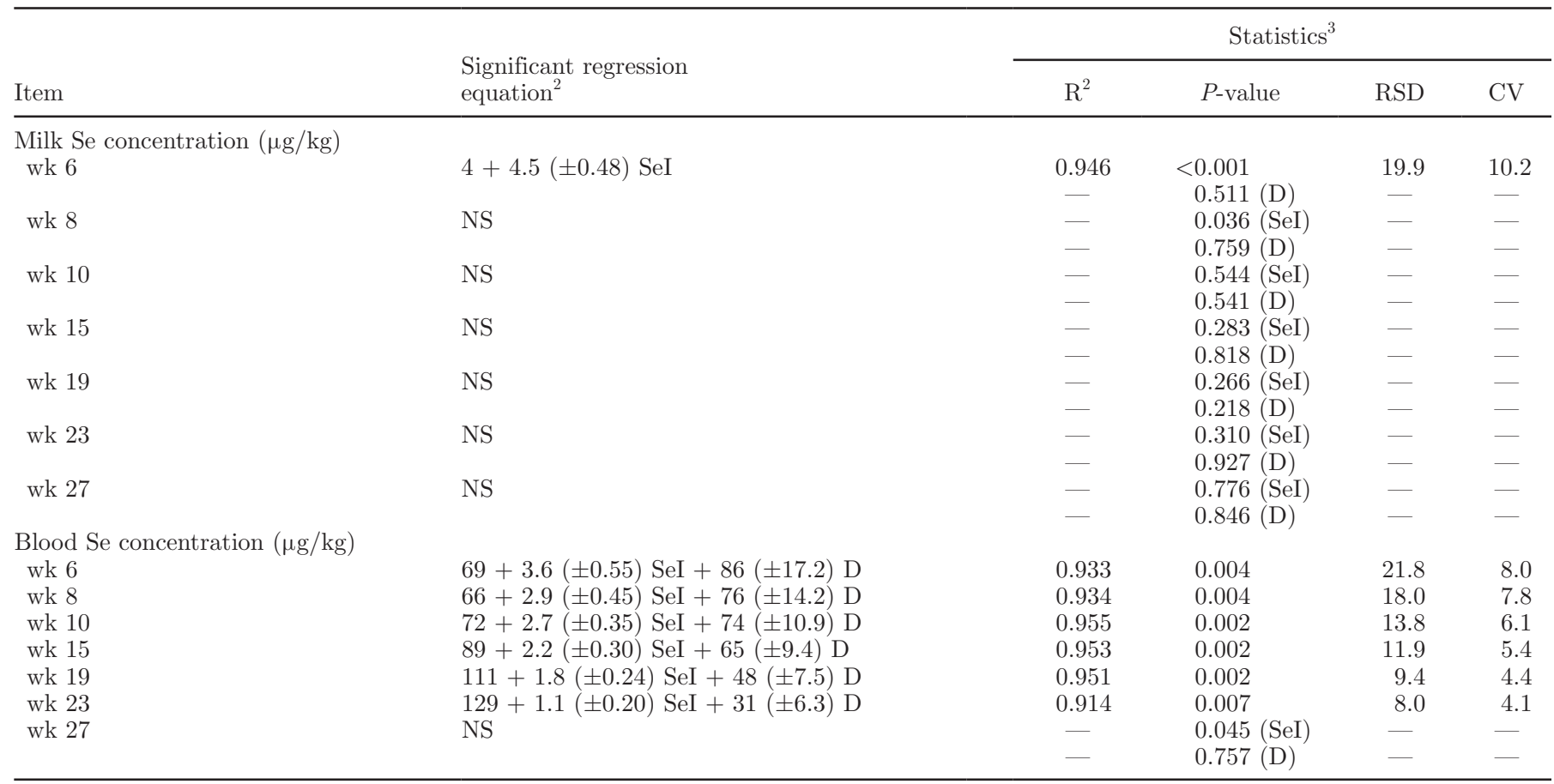

${ }^{1}$ These relationships describe the data presented in Figure 1 at each sampling time from the end of Se supplementation.

${ }^{2}$ Variables were only included if significant at $P<0.05$.

${ }^{3} \mathrm{RSD}=$ residual standard deviation. When either SeI or D was not significant, a $P$-value is given with the variable to which it applies in parenthesis. After applying a Bonferroni correction, the $P$-value for significance of an equation is 0.007 (see Materials and Methods for details). 
and meat animals (Juniper et al., 2008a). Importantly, signs of Se toxicity were not seen either, which is supported by reports of studies where greater amounts of Se were fed, and for longer periods. Davis et al. (2008) fed up to $34 \mathrm{mg}$ of Se/d to wether sheep (62-kg BW) for $60 \mathrm{wk}$, with the Se being provided by either selenite or Se yeast. Palacios et al. (2005) fed $125 \mathrm{mg}$ of Se/d as Se yeast to Holstein-Friesian cows for $60 \mathrm{~d}$, and recorded whole blood Se concentrations that reached $975 \mu \mathrm{g} /$ $\mathrm{kg}$, whereas Juniper et al. (2008a) fed high doses of Se yeast to dairy cows, beef cattle, calves, and lambs. None of these experiments recorded any adverse effects of Se supplementation.

\section{CONCLUSIONS}

After the withdrawal of Se supplementation of up to $60 \mathrm{mg}$ of Se/d for either 2 or 6 wk, milk Se concentrations responded very quickly to the change in the quantity of Se consumed, but duration of supplementation was not implicated, and any effect of Se intake had completely disappeared by 4 wk. In contrast to milk, blood Se concentrations continued to be affected by both amount and duration of Se supplementation for at least 4 mo after the withdrawal of supplementation, but by $5 \mathrm{mo}$, treatment effects had virtually dissipated. The slow decrease in blood Se concentrations after the withdrawal of supplementation would most likely be due to the protracted clearance of Se from the various tissues that had accumulated Se during supplementation and to the rate of erythrocyte turnover. Although postsupplementation milk Se concentrations are unlikely to create problems at the milk factory beyond $4 \mathrm{wk}$, the high residual blood/tissue Se concentrations that take considerably more time to dissipate provide the potential for possible unintended consequences at the food chain/farm environment level. If high Se supplementation is undertaken with the objective of producing Seenriched dairy products for the supra-nutritional intake of Se in humans, it is important that farmers are aware that Se can remain in the farming system for some time after the cessation of Se supplementation, and that this supplementation should only be considered for short periods.

\section{ACKNOWLEDGMENTS}

Funding provided by the Geoffrey Gardiner Dairy Foundation (Melbourne, Victoria, Australia) and the Victorian Department of Primary Industries is acknowledged. Valuable technical assistance was provided by Marg Jenkin and Stuart Austin (Kyabram Centre, Victorian Department of Primary Industries, Australia).

\section{REFERENCES}

Baird, D. B. 1994. The design of experiments with covariates. PhD Thesis. University of Otago, Dunedin, New Zealand.

Ceballos, A., J. Sánchez, H. Stryhn, J. B. Montgomery, H. W. Barkema, and J. J. Wichtel. 2009. Meta-analysis of the effect of oral selenium supplementation on milk selenium concentration in cattle. J. Dairy Sci. 92:324-342.

Combs, G. F., Jr. 2001. Selenium in global food systems. Br. J. Nutr. 85:517-547.

CSIRO. 2007. Nutrient Requirements of Domesticated Ruminants. M. Freer, H. Dove, and J. V. Nolan, ed. CSIRO Publ., Melbourne, Australia.

Davis, P. A., L. R. McDowell, N. S. Wilkinson, C. D. Buergelt, R. Van Alstyne, R. N. Weldon, T. T. Marshall, and E. Y. MatsudaFugisaki. 2008. Comparative effects of various dietary levels of Se as sodium selenite or Se yeast on blood, wool, and tissue Se concentrations of wether sheep. Small Rumin. Res. 74:149-158.

Doyle, P. T., C. R. Stockdale, M. L. Jenkin, G. P. Walker, F. R. Dunshea, P. M. Shields, and A. McKenna. 2011. Producing milk with uniform high selenium concentrations on commercial dairy farms. Anim. Prod. Sci. 51:87-94.

Earle, D. F. 1976. A guide to scoring dairy cow condition. J. Agric. (Victoria, Aust.) 74:228-231.

Givens, D. I., R. Allison, B. Cottrill, and J. S. Blake. 2004. Enhancing selenium content of bovine milk through alteration of the form and concentration of selenium in the diet of dairy cows. J. Sci. Food Agric. 84:811-817.

Heard, J., G. P. Walker, P. Royle, G. McIntosh, and P. T. Doyle. 2004 b. Effects of short-term supplementation with selenised yeast on milk production and composition of lactating cows. Aust. J. Dairy Technol. 59:199-203.

Heard, J. W., D. C. Cohen, P. T. Doyle, W. J. Wales, and C. R. Stockdale. 2004a. Diet check-A tactical decision support tool for feeding decisions with grazing dairy cows. Anim. Feed Sci. Technol. 112:177-194.

Heard, J. W., C. R. Stockdale, G. P. Walker, C. M. Leddin, F. R. Dunshea, G. H. McIntosh, P. M. Shields, A. McKenna, G. P. Young, and P. T. Doyle. 2007. Increasing selenium concentration in milk: Effects of amount of selenium from yeast and cereal grain supplements. J. Dairy Sci. 90:4117-4127.

Hu, Y., G. H. McIntosh, R. K. Le Leu, R. Woodman, and G. P. Young. 2008. Suppression of colon oncogenesis by selenium-enriched milk proteins: Apoptosis and K-ras mutations. Cancer Res. 68:49364944.

Juniper, D. T., R. H. Phipps, D. I. Givens, A. K. Jones, C. Green, and G. Bertin. 2008a. Tolerance of ruminant animals to high dose in-feed administration of a selenium-enriched yeast. J. Anim. Sci. $86: 197-204$

Juniper, D. T., R. H. Phipps, A. K. Jones, and G. Bertin. 2006. Selenium supplementation of lactating dairy cows: Effects on selenium concentration in blood, milk, urine, and feces. J. Dairy Sci. 89:3544-3551.

Juniper, D. T., R. H. Phipps, E. Ramos-Morales, and G. Bertin. 2008b. Selenium persistency and speciation in the tissues of lambs following the withdrawal of dietary high-dose selenium-enriched yeast. Animal 2:375-380.

Juniper, D. T., R. H. Phipps, E. Ramos-Morales, and G. Bertin. 2008c Effect of dietary supplementation with selenium-enriched yeast or sodium selenite on selenium tissue distribution and meat quality in beef cattle. J. Anim. Sci. 86:3100-3109.

Juniper, D. T., R. H. Phipps, E. Ramos-Morales, and G. Bertin. 2009. Effect of high dose selenium enriched yeast diets on the distribution of total selenium and selenium species within lamb tissues. Livest. Sci. 122:63-67.

Lemly, A. D. 2004. Aquatic selenium pollution is a global environmental safety issue. Ecotoxicol. Environ. Saf. 59:44-56.

Mayland, H. F. 1994. Selenium in plant and animal nutrition. Pages 29-45 in Selenium in the Environment. W. T. Frankenberger and S. Benson, ed. Marcel Dekker, New York, NY. 
McIntosh, G., F. Dunshea, T. McKenna, G. Walker, Y. Hu, J. Heard, R. Stockdale, M. Shields, G. Young, and P. Doyle. 2008. A dairy source of organic selenium for health and wellbeing. Food Aust. 60:132-134.

McIntosh, G. H., and P. J. Royle. 2002. Supplementation of cows with organic selenium and the identification of selenium-rich protein fractions in milk. Pages 233-238 in Nutritional Biotechnology in the Feed and Food Industries. Proc. Alltech's 18th Ann. Symp. T. P. Lyons and K. A. Jacques, ed. Nottingham University Press, Nottingham, UK.

Palacios, Ò., J. R. Encinar, G. Bertin, and R. Lobinski. 2005. Analysis of the selenium species distribution in cow blood by size exclusion liquid chromatography-inductively coupled plasma collision cell mass spectrometry (SEC-ICPccMS). Anal. Bioanal. Chem. 383:516-522.

Rayman, M. P. 2004. The use of high-selenium yeast to raise selenium status; How does it measure up? Br. J. Nutr. 92:557-573.

Schrauzer, G. N. 2003. The nutritional significance, metabolism and toxicology of selenomethionine. Adv. Food Nutr. Res. 47:73112.

Standing Committee on Agriculture. 1990. Feeding Standards for Australian Livestock. Ruminants. CSIRO Publ., Melbourne, Australia.

Stockdale, C. R., and H. S. Gill. 2010. Effect of pelleting of concentrates on milk and blood selenium concentrations in lactating dairy cows when selenised yeast is included in the diet. Anim. Prod. Sci. 50:371-375.
Stockdale, C. R., P. M. Shields, A. McKenna, G. P. Walker, F. R. Dunshea, and P. T. Doyle. 2011. Selenium levels in cows fed pasture and concentrates or a total mixed ration and supplemented with selenized yeast to produce milk with supra-nutritional selenium concentrations. J. Dairy Sci. 94:262-272.

Taylor, J. B. 2005. Time-dependent influence of supranutritional organically bound selenium on selenium accumulation in growing wether lambs. J. Anim. Sci. 83:1186-1193.

Uglietta, R., P. T. Doyle, G. P. Walker, J. W. Heard, C. M. Leddin, C. R. Stockdale, G. H. McIntosh, G. P. Young, H. S. Gill, and F. R. Dunshea. 2008. Bioavailability of selenium from selenium-enriched milk assessed in the artificially-reared neonatal pig. Nutr. Diet. 65(Suppl. 3):S37-S40.

Wales, W. J., D. W. Dellow, and P. T. Doyle. 1999. Degradabilities of dry matter and crude protein from perennial herbage and supplements used in dairy production systems in Victoria. Aust. J. Exp. Agric. 39:645-656.

Walker, G. P., F. R. Dunshea, J. W. Heard, C. R. Stockdale, and P. T. Doyle. 2010. Output of selenium in milk, urine, and feces is proportional to selenium intake in dairy cows fed a total mixed ration supplemented with selenium yeast. J. Dairy Sci. 93:4644-4650.

Weiss, W. P. 2003. Selenium nutrition of dairy cows: Comparing responses to organic and inorganic selenium forms. Pages 333-343 in Nutritional Biotechnology in the Feed and Food Industries. Proc. Alltech's 19th Ann. Symp. T. P. Lyons and K. A. Jacques, ed. Nottingham University Press, Nottingham, UK. 